Prof. Weiss, were received with much approval. Dr. Elkin reported parallax determinations of southern stars executed by him and Gill at the Cape, especially that of $a$ Centauri, which might be fixed at about $75 \mathrm{sec}$., and that of Sirius, which increased to $4 \mathrm{sec}$.

Pickering drew attention to photometric investigations carried out at the observatory of Harvard College. Janssen (Meudon) spoke on the observations which had been made in connection with the sun's eclipse of May 6 this year, discussed the photographs of the corona they had taken, and referred to the efforts made by Palisa with a vicw to discovering an intra-Mercurial planet, efforts which, as was well known, had yielded a negative result. Prof. Foerster gave an interesting account of observations made in the Berlin Observatory, by which he endeavoured to prove that the one ground-pillar of the Berlin Observatory on which investigations had hitherto been conducted had for the last twenty-five years been subjected to angular movements which were connected with the eleven years' period of solar spots. The annual averages of inclinations of the pillar from i 856 to $188 \mathrm{r}$ adhered as closely to Wolf's relative numbers as did the annual averages of the magnetic declination. From these facts Prof. Focrster drew the conclusion that very considerable effects could be traced from the radical changes of the eleven years' solar period. In connection with this communication of Foerster's, B. A. Gould reported how he had made quite similar observations on the sea-coast. Prof. Oppolzer (Vienna) spoke of investigations he had made in the Vienna Observatory with a view to determining the length of the seconds pendulum and the influence of the simultaneous oscillations of the stand. Foli gave an account of his examinations into the daily nutation and precession of the earth and his new tables of precession, and communicated some information regarding the observatory of Liege. Pechule (Copenhagen) sought to refute Stone's assertion that there was a difference of $1 \frac{1}{2}$ sec. between the former and the present Julian year, an assertion which had already been declared by Airy to be incorrect. He pointed out where Stone had committed an error in his calculations, and brought forward proof to show that the difference amounted to but four seconds every thousand years. Oudemans (Utrecht) corrected an assertion of Stone's that there was an error of $28 \mathrm{sec}$. in the reduction from median to sidereal time. Steinheil (Munich) referred to new constructions of telescopes calculated by him, and to the influence of the prism in the case of refracting telescopes on the sharpness of the image, in respect of the achromatism of the images, and to the means by which he counteracted the prejudicial effects in such cases.

On Sept. I 5 the members of the Congress visited the Observatory. The astronomers were highly satisfied with the arrangement of the observatory and the system of apparatus. The 27-inch instrument, supplied by Grubb of Dublin, and described in NATURE shortly after its completion, was an especial object of interest. Unfortunately the sky was clouded, so that it was impossible for the astronomers to carry out the observations they had intended with this powerful instrument. In reference to administrative matters we have also to mention Foerster's report on the conclusions of the International Commission respecting Kiel as an international centre, particularly in regard to the contributions of the respective astronomical institutes. On September 16 a social excursion was made to the neighbouring Kahlenberg, and this event was also made the occasion of the bapism of several newly discovered planets; the planet 234, discovered by Peters, rcceiving the name of Barbara; the three discovered by Palisa (Vienna) being called (229) Adelinda, (231) Vindobona, (225) Henrietta. It was resolved that the next meeting of the Society should be held at Geneva in 1885 .

\section{THE NORWEGIAN CIRCUMPOLAR STATION}

$\mathrm{I}^{\mathrm{T}}$ is with pleasure that $\mathrm{I}$ respond to the invitation of NATURE to give an account of our labours here during the last twelve months, and I may, in doing so, state that $I$ have purposely delayed writing these lines, in order to be able to give the result of our rescarches during a whole year.

The Norwegian Government have contributed their share to the international research of the physical conditions of the Polar regions by the establishment of the observatory here at Bossekop in Alten (Finmarken). The station, which is situated at the bottom of the Alten Fjord in $69^{\circ} 5^{8}$ lat. and $23^{\circ} 15^{\prime}$ long., commenced its labours on August 1, I882, which are to be continued until September I, 1883 , in accordance with the programme of the Polar Congress held in St. Petersburg in 188r. The equipment and instruments of the station, as well as its whole organisation, are also in accordance with the principles formulated by the Polar Congresses held in Hamburg in 1879 , in Bern in 1880 , and in St. Petersburg in $188 \mathrm{I}$. The personnel of the station consists of the writer as chief, Doctors C. Krafft, sub-chief, J. Schroeter and $\mathrm{F}$. Hesselberg, observers, and Herr O. Hagen, instrument maker and caretaker.

The obligatory observations embrace astronomical observations, readings every hour of the meteorological and magnetic variations, absolute measurements of the terrestrial current's three components, and studies of the aurora borealis. For the hourly observations the day and night have been divided into four watches of six hours each, which are taken by each one in turn.

In order to effect the astronomical observations, i.e. the determination of time and place, a small observatory $25 \mathrm{~m}$. in length, breadth, and height has been erected of deals, the roof and the southern and northern walls of which are provided with shutters to be opened during meridian observations. On a fixed pillar in the centre is placed a universal instrument by Repsold, besides which we possess three box chronometers by Frodsham, Kessels, and Mewes, the last named being regulated by star time, as well as two pocket chronometers by Kessels and Bröcking.

The weather during the winter and certain other circumstances have to some extent affected the astronomical observations, so that for the determination of time only a few meridian passages have been observed; but this circumstance is of no consequence whatever, as the station is independent of local determination of the time for ascertaining the absolute time, viz. the common mean time of Göttingen, which has been adopted at all the Polar stations as the common time, and which we receive from the observatory at Christiania through the telegraph office, about ten minutes distant, twice a week, at 9 a.m. on Sundays and 8 a.m. on Wednesdays, Greenwich time.

We have, however, a few meridian passages and observations of time with corresponding sun altitudes, which may be used for the verification of the longitude of the place. The Polar altitude has been verified by the measuring of circummeridian altitudes of the sun and Polaris. The universal instrument has also been employed for the determination of azimuth for the observations of the aurora borealis and the magnetic declination.

Of magnetical instruments we have a set for the determination of the elements of the terrestrial current, viz. a unifilar magnetometer by Elliott Brothers of London, and a Dover inclinatorium, both verified at Kew. The variation instruments, which are constructed on Lamont's principle by Prof. Mohn, and cxecuted by Herr C. Olsen, optician, of Christiania, consist of a variation instrument, a unifilar apparatus with two fixed deflectors for the observation of the variations of the horizontal intensity, and a unifilar apparatus with vertical bars of soft iron as deflectors, whose magnetic moment varies accord- 
ing to the changes in the vertical intensity. We have $t$ wo sets of these instruments exactly similar in construction, of which one is kept in reserve. All the magnetical instruments are erected in the magnetic observatory in the manner shown in the diagram (Fig. 1). This observatory is divided into three sections, and arranged as follows:-Furthest to the east is the variation chamber, which has, in order to make room for both sets of instruments, been made rather large, viz. $75 \mathrm{~m}$. long, $5 \mathrm{~m}$. wide, and $2.8 \mathrm{~m}$. high. It has been constructed partly under the earth's surface, the ground having been hollowed to a depth of about I m., where the floor has been laid, and the mould cast up along the outer sides of the hut, which have first been covered with birch bark, and in turn by turf. The roof has first been covered with fireproof paper, and then with turf and mould, which gives to the observatory the appearance of a subterranean chamber. The object of this is, of course, to keep the temperature in the room as constant as possible, which we have in fact fully succeeded in doing, as the diurnal variations have seldom exceeded $5^{\circ}$ to $6^{\circ} \mathrm{C}$., while averagely the temperature during twenty-four hours has only varied from $2^{\circ}$ to $3^{\circ}$. The lowest temperature registered in the chamber during the winter was $-3^{\circ} \mathrm{C}$. during a high wind, while the highest during the summer was $23^{\circ} \mathrm{C}$. Of windows there are none; but lighting is effected by means of four petroleum lamps, which are kept

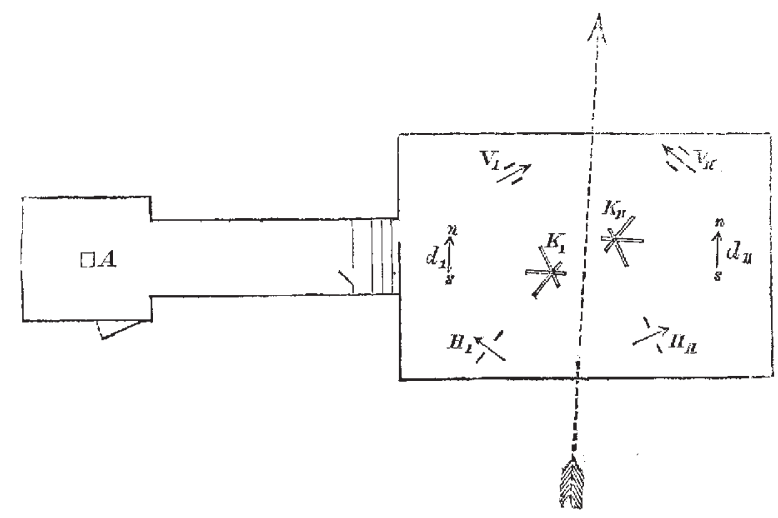

FIG. x.-Diagram showing the plan of the Magnetic Observatory. $d_{x} d_{\mathrm{II}}$, variation instruments for the declination; $H_{\mathrm{I}} H_{\mathrm{rr}}$, variation instrument for the horizontal intensity; $V_{\mathrm{I}} V_{\mathrm{I}}$, variation instruments for the vertical intensity: $K_{T} K_{x x}$, the reading telescopes; $A$, pillar for absolute measurements; $\longrightarrow$, magnetic meridian.

burning day and night, and to the faint heat emitted by these I ascribe the circumstance that the average temperature during the winter was several degrees above freezingpoint, and this under an open-air temperature of $-20^{\circ} \mathrm{C}$. From the great variation chamber a small ladder leads through an aperture in the western cross wall up into a narrow corridor $5 \mathrm{~m}$. by $\mathrm{I} \cdot 5 \mathrm{~m}$., which opens into the chamber for the absolute measurements. This is $2.5 \mathrm{~m}$. in length, width, and height, and from this a door leads out into the open, while it is also provided with a small window in the western wall. In the corridor is a partition with a door, in order to prevent as much as possible any change in the temperature in the variation chamber. The building is constructed of rough deals, while the use of iron has, of course, been carefully avoided. The whole has been joined by means of wooden pegs, and the roofpaper fastened with copper nails. The lamps have been hung on brass wire or placed on wooden tripods; while the hinges of the doors are of brass, and the handles of wood.

In the variation chamber eight pillars have been raised of iron-free bricks and cement. These pillars rest on large slates, which have been laid at a depth of about 7 decimetres below the floor, and run free through openings in the floor. The tops of the pillars have a marble slab attached to them, on which the instruments are placed, viz. one on each of the six pillars, and a reading telescope on each one of the remainder.

The needles in the six instruments are exactly alike in size as well as in magnetic moment. They are made of lamellar watch-spring, separated by three small bits of brass, and are about $9 \mathrm{~cm}$. in length. Above the needle, and parallel with the same, a mirror is affixed, from which the image of the scale (paper on spruce wood), placed perpendicularly on the reading telescope, is reflected in the focus of the telescope. Each scale is one metre in length, but even this comparatively great length has, as regards the intensity instruments, been found insufficient during great perturbation, and we have been compelled to lengthen the scale on the side most exposed by adding an auxiliary scale. The scale is divided into millimetres, the distance between mirror and scale being exactly I7 $19 \mathrm{~mm}$, making the value of the angle of one part of the scale exactly $\mathbf{I}^{\prime}$. The reading telescopes of the two sets are fixed on a common vertical axis, the one for horizontal intensity being highest, the one for declination in: the centre, and the one for vertical intensity lowest. This is also the order in which the instruments are read, a reading of all three being easily effected in fifteen to twenty seconds.

The regular magnetic variation observations are, as previously stated, effected every hour, seven readings being taken of each instrument. At fixed terms, viz. on the Ist and the 15 th of the month, readings are effected every fifth minute, while, during a certain bour of these two days, the variations of the declination and the horizontal intensity are read cvery 20 th second. Magnetic disturbances, some cven of great violence, have during the twelve months been the order of the day here. Thus when perusing our " $\log$," one will hardly find five days in average in each month during which the needle has remained completely at rest throughout twenty-four hours. Little jerks or oscillations have constantly occurred, particularly during the night, when the disturbance has generally been greatest, and it has not been an uncommon occurrence that the readings have fallen out on the auxiliary scale, oftencst; however, as regards the vertical intensity.

The zero of the variation instruments is partly controlled by direct simultancous observations of both systems, compared once a weck, and partly by absolute measurements of the three terrestrial magnetic elements effected scveral times during the month. The unifilar magnetometer is employed for determining the declination as well as the horizontal intensity, the latter embracing both vibratory motions and deflections with the magnet deflector at two different distances. The effect of the torsion on the position of the declination needle is also determined by deflections in the manner advocated by Lamont in his "Handbuch der Frdmagnetismus" \$9I. The inclinometer is provided with four needles, of which three are in use, and during the last half year all three have been used during inclinatory observations, which have given results with a pretty uniform difference. As a matter of course, every reading during absolute measurements has been accompanied by a stringent and simultaneous reading of the corresponding variation instruments.

For the study of the aurora borcalis we have employed a theodolite which has been constructed by Prof. Mohn, and finished by Herr C. Olsen. The theodolite has an excentrically attached conic tube, which serves as drop. The small ocular end is closed by a disk in which is a circular holc a little larger than the pupil of the eye. The objective end, which forms the basis of the conus, is completely open, with a cross of thin steel wire suspended therein. The one half of the curved surface of the tube, the ocular part, is a solid brass pipe, while the 
other half, the objective part, is constructed in open trellis work, partly in order that the wire cross may easily be seen when a lantern is held at its side, and partly on account of the balance. The horizontal as well as the vertical circle, is provirled with noninus, whereby $\mathrm{IO}^{\prime}$ is read directly and $I^{\prime}$ may casily be ascertained. To the horizontal axis belongs a libella, on which each part represents $I^{\prime}$. A massive base of cast-iron-a vertical column with three projectors at the foot, each one with a foot-screwgives the instrument an exceedingly solid rest, and keeps the due level for weeks when the instrument is not subjected to gales or other violent exterior influences. Our station possesses two such theodolites, while the Swedes at Spitzbergen have three, the Dutch on board the Varna two, and Dr. Sophus Tromholt, at Kautokeino, one.

Auroræ have been seen here during the winter almost every night, and during all weathers, thus, even behind cumulo-stratus clouds, oscillating waves of the aurora borealis have at times been observed. Proper measurements have, however, of course only been effected on clear nights. With Dr. Sophus Tromholt, who has, as the readers of NATURE know, from his communications to this journal, during the winter sojourned at Kautokeino specially for his researches on the aurora borealis, we have arranged to measure at agreed periods the elevation of the aurora in the common plane KautokeinoBossekop. We have effected a number of such mea surements here, which will, I believe, give important results as regards this phenomenon, when compared with those made by Dr. Trombolt. A closer auxiliary station for parallax measurements was also contemplated here, and to this end I had a pillar raised in an open place for a theodolite, about seven kilometres south of our station, but the want of telephonic connection and assistants, I regret to say, prevented this project from being carried out.

The auroral forms or types which have appeared here bave been those generally known, from the grand corona to the modest pulsating little luminous cloud, but as a charact sristic feature attending them all I must mention

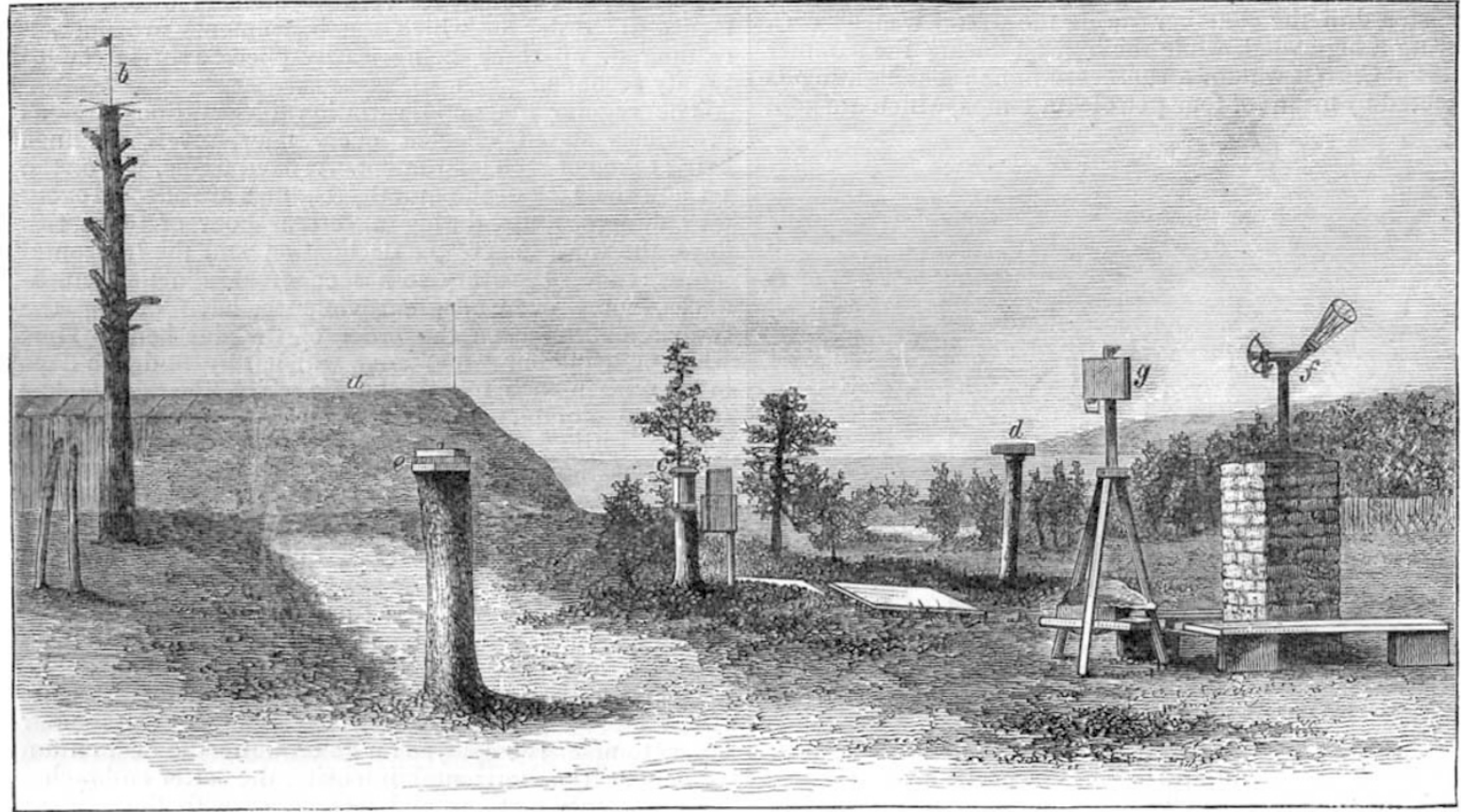

FIG. 2.-The Norwegian Circumpolar Station at Bossekop. $a$, magnetic observatory; $b$, yane ; $c$, rain-gange ; $d$, black-ball thermometer ; $e$, transit instrument: $f$, auroral theodolite; $g$, instrument for recording the auroral observations.

the absence of stability in the types. Thus only on a few occasions has there been an opportunity of watching the quiet stationary arc, but in general the auroræ have represented wafting draperies and shining streamers with ever-changing position and intensity.

As often as there has been an opportunity, spectroscopic researches have been effected with a Wrede's spectroscope. The well-known yellow-green auroral line has always been observed, and on one occasion also the red, the position of which we succeeded in fixing approximately in the spectroscope.

The meteorological instruments with which we have been furnished are similar to those in use at the meteorological observatory in Christiania. A $\mathrm{Kew}$ stationbarometer (Adie) is employed at the hourly observations, while a Fortin barometer (Secretan) serves as normal and control barometer. Generally a few times a week both barometers, which hang parallel in the office of the station, are compared. As a reserve instrument we have an aneroid, but this we have fortunately had no need of using.

For the protection of the thermometers we have erected a wooden cage on four poles facing the north, with biinds, a double back wall and a roof, exactly in conformity with Wild's model. In the centre of the cage is the actual thermometer box placed, of sheet ixon and with a free circulation for the air, in which is to be found dry and wet thermometers (divided into $0^{\circ}{ }_{2}$ C.) , as well as maximum and minimum ones. All the thermometers, which were manufactured by Aderman of Stockholm, have several times during the winter been examined as to the stability of zero, which has always been found pcrfectly correct. Besides these a black-ball thermometer has during the summer been erected, and read several times a day. Psychrometer readings have on some occasions been controlled at low temperatures by observations with Allnard's modified form of Regnault's hygrometer (Golaz, Paris); while absolute determinations of moisture 
through weighing have been attempted by Dr. Krafft with a chemical weight (Bunge), however without result, caused chiefly by the circumstance that he was unable to give the instrument the proper rest. The observations of the directions of the wind have been made by a weather-cock fixed on the top of a stripped fir tree, the force being registered by Beaufort's scale, and the velocity partly by Mohn's hand thermometer, which are used during the hourly observations, and partly by means of a Robinson anemometer placed on the roof of the dwelling-house, which is read once in twenty-four hours. Further, one of Hageman's anemometers is erected in the office, from which the conductor, made of indiarubber and lead pipes, is carried outside the house and along the flagstaff in such a manner that the absorbing point or tube is situated a couple of centimetres above the knob of the same. The observations with this anemometer have, however, not given so satisfactory results as might have been expected from my experiences in other places. The cause of this is no doubt the circumstance that the instrument used was not a new one, and consequently, perhaps, not very sensitive, while the position was, we found, not the most advantageous. On the bare ground we have placed two rain-gauges - the one square and the other roundwith a receiving surface of 225 square $\mathrm{cm}$. each. The rainfall here is very small, averaging only $267 \mathrm{~mm}$. per year, but during the past twelve months it has been rather less.

The measurement of the snowfall we have found almost an impossibility, on account of the frequent gales during the winter, which sweep the snow away as quicksand from one place and deposit large drifts in others.

Every month measurements of the temperature of the sea have been effected, in the Alten Fjord, with one of Negretti and Zambra's deep-sea thermometers. The depth is Ioo English fathoms, and the temperature read at every tenth fathom. We have during these researches discovered that from the bottom and Io to 20 fathoms upwards the temperature keeps constant throughout the year, whereas in the layers above this depth some very interesting variations occur with the seasons.

Last winter here has been milder than we anticipated, the lowest temperature registered being $-21^{\circ} \cdot 7 \mathrm{C}$., which was read by the minimum thermometer at 8 a.m. on December 31 , 1882 . Under high wind such a temperature is unpleasant enough, and with gales we have several times been favoured. Thus, on October 5 the velocity of the wind under a storm from the north-west was 26 metres per second, and on later occasions the anemometer has not seldom shown a velocity of from Io to 20 metres per second.

Our labours at this station are now approaching their completion, and it is satisfactory to me to be able to state that no accident has occurred to our instruments, the accuracy of which has been controlled throughout in various manners, and that the scientific researches have been continued during the entire year without a single interruption.

What the ultimate results of our researches during our sojourn here will be it is of course at the present moment an impossibility for me to state, but I feel confident that, when all the materials of research have been collected from the various circumpolar stations and compared, it will be found that the Norwegian station at Bossekop has formed an important link in the chain of international meteorological research around the Pole.

Bossekop, Finmarken, Norway, August

\section{A NATIONAL LABORATORY OF MARINE ZOOLOGY}

$\mathrm{I}_{\mathrm{T}}$ is pretty well understood that the Executive Committee of the London International Fisheries Exhibition of 1883 will have a sum of money in hand when all expenses connected with the Exhibition are paid, amounting to some thousands of pounds. The gentlemen who have organised and carried through this very successful enterprise are to be congratulated on the popularity which has attended the Exhibition and on the amount of interest which they have excited in all classes of the community in matters relating to our national fisheries. Not only this, but the Committee deserves hearty thanks for the valuable series of pamphlets on subjects connected with fisheries which it has printed and circulated far and wide. These pamphlets are for the most part reports of lectures delivered by highly competent specialists at the "Conferences" inaugurated by Prof. Huxley under the presidency of the Prince of Wales, and amongst them are such important essays as that of Prof. Hubrecht on oyster culture, of Dr. Day on the food of fishes, of Prof. Brown Goode on the fishery industries of the United States, and of Mr. Duff on the herring fisheries of Scotland.

It is not surprising that at the present moment suggestions should be offered from various sides to the Exhibition Committee with reference to the best use of the surplus funds in its hands. No one will pretend for a moment that the Committee has not the full right to make what use of those funds it may deem most fitting; and the public has every reason to feel confidence that the ultimate decision of the Committee will be made with the intention of doing what is best for the national interests bound up with our fishery industries. At the same time it is a legitimate thing for men of public position and responsibility to place before the Committee suggestions as to useful modes of employing the surplus funds in its hands. Accordingly we note with satisfaction that a number of our leading biologists, whose opinion upon this matter is certainly entitled to very great weight, have placed before the Committee a suggestion for the foundation of a laboratory upon the British coast, which shall be devoted to the study of marine animals and plants in relation to fisheries. A similar proposal has also been independently placed before the Exhibition Committee by the executive of the British Association for the Advancement of Science.

It is a very striking fact that the one point in which all speakers at the Conferences held during the past summer at the Exhibition were agreed was this: that our knowledge of the habits, time, and place of spawning, food, peculiarities of the young, migrations, \&c., of the fish which form the basis of British fisheries, is lamentably deficient, and that without further knowledge any legislation or attempts to improve our fisheries by better modes of fishing, or by protection or culture, must be dangerous, and indeed unreasonable. Prof. Brown Goode, the United States Commissioner, declared at the Conference on July 20 that "the spread of actual scientific knowledge concerning fish and fisheries was one of the things which, above all others, would be the most profitable and satisfactory outcome of this Exhibition." At the same Conference Prof. Hubrecht, the Netherlands Commissioner, said that "he endorsed from the bottom of his heart the principle that there must be inquiry, and still further inquiry, before legislation based on scientific and accurate principles could be carried out. They must take as a motto, more knowledge, more science, more zoology." On the same occasion the Duke of Argyll referred to the suggestion which had been submitted to the Conference to the effect that the foundation of a laboratory of marine zoology might well be undertaken by those who had organised and carried out the International Fisheries Exhibition. Speaking with the authority of one well acquainted with the Scotch herring fisheries, as well as with the knowledge of an accomplished naturalist, he stated that in his judgment this suggestion was a most important one, which be hoped would be brought forward in the proper quarter, and that he should give all the help he could in the matter. 